\title{
Martin Hurcombe, France and the Spanish Civil War. Cultural representations of the war next door, 1936-1945
}

Farnham, Ashgate, 2011, 245 p.

Michael Löwy

\section{OpenEdition}

Journals

Édition électronique

URL : http://journals.openedition.org/assr/25520

DOI : $10.4000 /$ assr. 25520

ISSN : $1777-5825$

Éditeur

Éditions de l'EHESS

Édition imprimée

Date de publication : 30 décembre 2013

Pagination : 220

ISSN : 0335-5985

Référence électronique

Michael Löwy, « Martin Hurcombe, France and the Spanish Civil War. Cultural representations of the war next door, 1936-1945», Archives de sciences sociales des religions [En ligne], 164 | 2013, mis en ligne le 05 mars 2014, consulté le 21 septembre 2020. URL : http://journals.openedition.org/assr/ 25520 ; DOI : https://doi.org/10.4000/assr.25520

Ce document a été généré automatiquement le 21 septembre 2020.

(c) Archives de sciences sociales des religions 


\section{Martin Hurcombe, France and the Spanish Civil War. Cultural representations of the war next door, 1936-1945}

Farnham, Ashgate, 2011, 245 p.

Michael Löwy

\section{RÉFÉRENCE}

Martin Hurcombe, France and the Spanish Civil War. Cultural representations of the war next door, 1936-1945 Farnham, Ashgate, 2011, 245 p. 
1 Cet intéressant ouvrage utilise le concept d'utopie selon Mannheim pour examiner les représentations culturelles - en fait littéraires - de la Guerre d'Espagne en France. L'utopie, rappelle-t-il, n'a pas besoin d'être pratiquement réalisable, elle a simplement besoin d'être considérée comme telle pour mobiliser vers l'action politique. Les utopies en question, aussi bien en Espagne qu'en France, peuvent être révolutionnaires ou contrerévolutionnaires, nationalistes ou socialistes, athées ou croyantes. Les travaux de sociologie de la littérature de Lucien Goldmann et Georg Lukacs incorrectement orthographié, de forme systématique, comme "Luckaks » - sont aussi mobilisés. Des romans fascistes, comme ceux de Drieu La Rochelle et

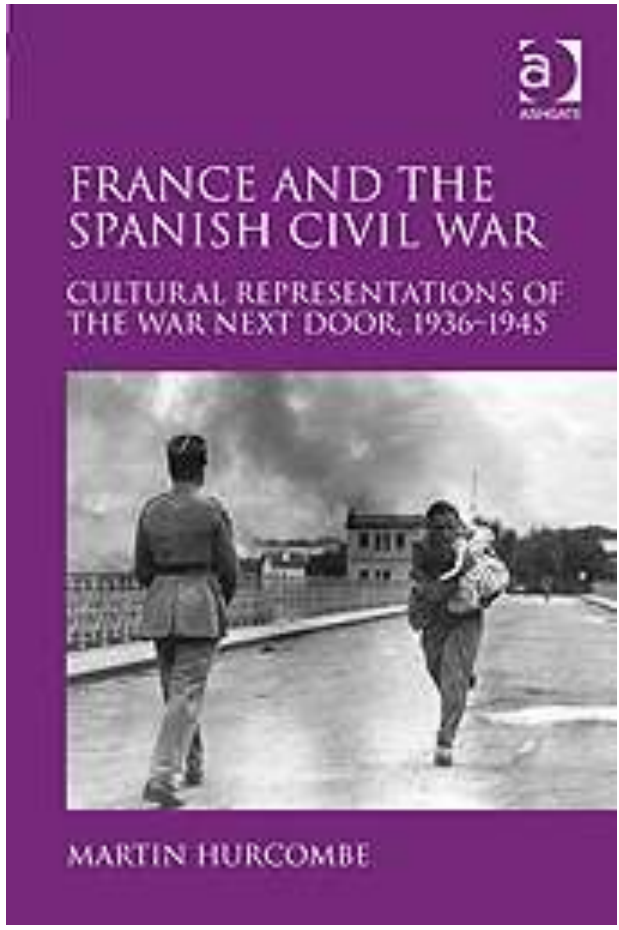
Brasillach, ou antifascistes - notamment L'Espoir de Malraux - occupent une place centrale dans les analyses du livre.

La religion n'est pas absente de cet affrontement entre utopies antagoniques. Déjà Paul Claudel, dans son poème «Aux Martyrs Espagnols» (1937) célébrait ces combattants chrétiens contre l'athéisme de «Voltaire, Renan et Marx ». Plus étonnant, dans le roman El Requeté (1937) d'un écrivain réactionnaire bien oublié aujourd'hui, Lucien Maulvault, à la gloire de la milice catholique monarchiste - les carlistes - on trouve ce commentaire peu religieux: "Qu'importe, au fond, leur Dieu, leurs convictions étroitement dévotes. Une seule chose suffit à nous unir : cette conscience infuse de la prépondérance des choses de l'esprit... ». Inversement, la dimension religieuse n'est pas absente de l'autre côté de la barricade. Ainsi, dans L'Espoir de Malraux, un officier républicain catholique, Hernandez, décrit les miliciens révolutionnaires comme des « demi-chrétiens » motivés par le « goût du sacrifice ».

Cependant, le chapitre le plus intéressant de ce livre, du point de vue de l'histoire de la culture religieuse en France, c'est sans doute celui dédié aux Grands Cimitières sous la lune (1938) de Georges Bernanos. Comme l'on sait, Bernanos, écrivain catholique fervent, partisan de la restauration de la monarchie absolue - et donc proche de l'Action Française - va dénoncer, avec une totale intransigeance, les atrocités des nationalistes espagnols (les partisans de Franco) auxquelles il a assisté dans l'île de Majorque en 1936-1937. Pour lui, la soi-disant «Croisade » des nationalistes n'est qu'un masque occultant les intérêts de l'ordre bourgeois établi, de la classe des propriétaires, motivés par «l'esprit de Peur et l'esprit de Vengeance». La plus grande trahison spirituelle est, pour l'écrivain catholique français, la complicité de l'Église espagnole avec la terreur nationaliste, et la tentative de lui attribuer un caractère religieux. Il n'hésite pas à parler, à propos de ce pouvoir corrompu, d'« ordre satanique fondé sur une force illégitime », et donc, une expression de « l'anti-Christ». 